\title{
Forum
}

\section{Möjligheter och svårigheter för kritisk forskning i socialt arbete}

Tina Mattsson är socionom, genusvetare och docent i socialt arbete vid Socialhögskolan, Lunds universitet.

Kontakt: tina.mattsson@soch.lu.se

\section{Inledning}

En av de mest tummade och nedklottrade metodböcker jag har är ett gammalt exemplar av organisationsforskarna Mats Alvesson och Stanley Deetz (1999) Kritisk samhällsvetenskaplig metod. Jag minns när jag läste den som doktorand, jag kände spänning och nyfikenhet. Alvesson och Deetz talade om den samhällsvetenskapliga forskningens kritiska potential och om målet att bedriva forskning som förmår ifrågasätta snarare än bekräfta, rubba snarare än fortplanta och blottlägga snarare än bevara (Alvesson \& Deetz 1999 s. 13). Jag häpnade - och sveptes med. Var detta en möjlig vetenskaplig ambition? Jag kände å ena sidan igen tongångarna från de genusvetenskapliga studier jag bedrev parallellt med mina doktorandstudier, men jag kände inte igen mig i den vetenskapliga miljö jag befann mig i som doktorand inom socialt arbete. Där betonades att kvalitativ forskning (som var den metodologiska tradition jag rörde mig inom) utvecklade teorier och resultat genom gedigna empiriska studier, där data talade för sig själva och var det som visade vägen till teoretiska resultat (jfr Alvesson \& Deetz 1999 s. 9). Teoretiska uppslag i studiers initialskede antogs generera alltför ensidiga tolkningar, med risk att inte kunna återspegla den verklighet de avsåg att belysa. Ambitioner att generera kunskap som kunde bidra till förändring uppfattades som politiska, förutbestämmande och styrande. Risken för så kallad bekräftelseforskning, där egna antaganden och intressen kom att gå 
före vetenskaplig objektivitet och empiriskt grundade beskrivningar av "världen", ansågs stor om teorier användes för mycket eller om förändringsintresse var en del av forskningsambitionen. Forskning skulle generera teorier och begrepp, inte styras av dem. Jag kände mig förvirrad, eftersom jag var teoretiskt intresserad, ville undersöka den feministiska teorins användbarhet inom socialt arbete och dessutom gärna ville bidra till nya förståelser av det sociala arbetets praktik. Mina drivkrafter ifrågasattes som ovetenskapliga. När jag läste Alvesson och Deetz förstod jag att det fanns en samhällsvetenskaplig tradition inom vilken jag med mina forskningsambitioner och mitt genusvetenskapliga perspektiv kunde rymmas. Jag upplevde dock inte att denna tradition fanns inom forskningen i socialt arbete. Fortfarande, 20 år efter att jag påbörjade mina forskarstudier, upplever jag att den inte riktigt etablerat sig inom ämnet. Även om intresset för den definitivt ökat och en rad viktiga och intressanta studier genomförts (t.ex. Ekström 2016; Eliassi 2010; Herz 2012; Johansson 2006; Söderman 2019; Wikström 2007), stöter jag kontinuerligt på kollegor som i sin ambition att bedriva just kritisk forskning i socialt arbete upplever en akademisk ensamhet och brist på erkännande inom ämnet. Fler än jag tycks önska sig en tydligare kritisk forskningstradition i socialt arbete, inte minst önskar jag själv en starkare etablering av dess specifika konkretiseringar i form av genusvetenskapliga, postkoloniala, queeroch cripperspektiv. Perspektiv som jag menar skulle möjliggöra en viktig kritisk och analytisk blick i förhållande till de sociala problem vi som forskare i socialt arbete intresserar oss för. De skulle bidra till angelägna analyser i ett globaliserat samhälle där den strukturella ojämlikheten ökar och där en nyliberal diskurs har tolkningsföreträde i förhållande till hur sociala problem förstås. Analyser som skulle kunna utmana de maktordningar som dessa ojämlikheter grundar sig i.

Det är mot den bakgrunden jag vill undersöka glappet mellan den kritiska forskningens vetenskapliga ambitioner och den forskningstradition jag är en del av som forskare i socialt arbete. Mitt syfte är att diskutera hur vi kan förstå att den kritiska forskningstradition som Alvesson och Deetz definierar haft svårt att etablera sig inom forskningsfältet socialt arbete $i$ Sverige. Jag gör det genom att utgå från de många likheter, men också skillnader, som finns mellan de båda forskningsområdena socialt arbete och genusvetenskap. Jämförelsen med genusvetenskapen ger exempel på ett forskningsområde som har många likheter med socialt arbete, båda är exempelvis vetenskapliga discipliner som i Sverige började utvecklas under 1980-talet, de är tvärvetenskapliga samt har kopplingar till politiska ambitioner om samhällsförändring. Som vetenskapligt ämne och forskningsfält har dock genusvetenskapen utvecklats i en tydligare kritisk samhällsvetenskaplig riktning. Jämförelsen gör att jag kan undersöka varför kritiska samhällsvetenskapliga perspektiv skulle kunna vara möjliga inom socialt arbete, men också varför de tycks ha haft svårt att etablera sig inom fältet. I min diskussion har jag tagit hjälp av texter som behandlar socialt arbete och genus- 
vetenskap som forskningsområden och akademiska ämnen (t.ex. Brante 1987, 2003; Dellgran \& Höjer 2006; Gothlin 1999; Nygren 2016; Smirthwaite 2005: Sunesson 2016). Jag har inte minst inspirerats av en äldre text skriven av en forskare i socialt arbete: Berit Sundström Grinups. Grinups (1999) diskuterar parallellerna mellan socialt arbete och feministisk forskning, något som bidragit till min förståelse av hur likheter och skillnader mellan dem kan förstås och hjälpt mig utforska varför den kritiska samhällsvetenskapliga traditionen är mer utvecklad inom genusvetenskapen än inom socialt arbete.

Jag inleder artikeln med att kort beskriva den kritiska samhällsvetenskapens ambitioner. Därefter tar jag mig an diskussionen om hur vi kan förstå den kritiska forskningens möjligheter och svårigheter i socialt arbete. Jag gör detta genom fyra avsnitt. I det första och andra redogör jag för framväxten av socialt arbete respektive genusvetenskap som forskningsområden och akademiska ämnen. I det tredje och fjärde beskriver jag de likheter som jag menar borde placera båda ämnena inom den kritiska samhällsvetenskapliga forskningstraditionen, men också de skillnader som delvis leder till områdenas olika förhållningssätt till den. Avslutningsvis för jag ett resonemang om hur närheten till praktikerfältet och en begränsad vetenskapskritisk diskussion genererar svårigheter att etablera kritisk forskning i socialt arbete. Jag börjar dock med att förklara vad jag menar med "socialt arbete som forskningsområde" och "genusvetenskaplig forskning".

\section{Benämning av vetenskapliga fält}

I artikeln förhåller jag mig å ena sidan till forskningsområdet och forskningen i socialt arbete och å andra sidan till den genusvetenskapliga forskningen. Var gränserna går för dessa områden samt vilken forskning som inkluderas och exkluderas i förhållande till dem är inte helt enkelt att definiera (se t.ex. Thurén 2003; Sunesson 2016). Socialt arbete och genusvetenskap som akademiska ämnen är dock relevanta kontexter för min diskussion; med socialt arbete som forskningsområde avser jag därför den forskning som bedrivs inom ämnet och vid landets olika institutioner för socialt arbete (jfr Dellgran \& Höjer 2013). Med genusvetenskap och genusvetenskaplig forskning menar jag på liknande sätt den forskning som bedrivs inom ämnet genusvetenskap och vid landets genusvetenskapliga institutioner (Thurén 2003 s. 19; Högskoleverket 2007).

\section{Kritisk samhällsvetenskaplig forskning}

Vad är det då jag talar om när jag talar om kritisk samhällsvetenskaplig forskning, all forskning är väl i grunden kritisk? Jo, i alla fall i en bemärkelse. All vetenskap intar den kritiska utgångspunkten att inte godta påståenden utan noggrann kontroll av grunderna för dem. Vetenskap handlar om att skilja tillförlitlig kunskap från tro och föreställningar. Vetenskap bygger på ett kritiskt förhållningssätt både till vad vi tror oss 
veta och till hur vi går till väga för att undersöka och beforska världen. Den kritiska blicken och det kritiska förhållningssättet grundas bland annat genom etablerade diskussioner om vad kunskap är och vad vi kan veta, av vetenskaplig metod och av utarbetade former för granskning av vetenskapliga resultat. Mot den bakgrunden är all forskning kritisk. Mycket samhällsvetenskaplig forskning har dessutom omfattande kritiska ambitioner vad gäller att bidra med nya förståelser och kritisk granskning av samhällsfenomen och samhällsinstitutioner. Inte minst finns i socialt arbete en lång och viktig tradition av att synliggöra miss- och maktförhållanden samt olika former av samhälls- och organisationsproblem (jfr Alvesson \& Deetz 1999 s. 12). Den kritiska samhällsvetenskapliga forskning som Alvesson och Deetz (1999) lyfter fram vill dock nå längre än så. Med kritisk avses inom denna att rikta fokus mot sociala institutioner, ideologier och diskurser och att undersöka om och hur dessa inskränker människors fantasi, autonomi och beslutsfattande. I fokus är asymmetriska maktrelationer samt antaganden som tas för givna. Målet är att bedriva forskning som förmår ifrågasätta snarare än bekräfta det etablerade. Att bidra till att rubba snarare än fortplanta kulturella traditioner och konventioner. Forskningen blottlägger och demonstrerar spänningar i användningen av språket snarare än att bevara dess dominans. Tanken är också att uppmuntra meningsskiljaktigheter snarare än att utgå från samförstånd. Det övergripande målet är att rubba den rådande sociala verkligheten och bidra till frigörelse från eller motstånd mot det som dominerar eller hindrar människor från att fritt fatta beslut (Alvesson \& Deetz 1999 s. 9, 13). Teori betonas som viktig för att förstå sociala fenomen och den fyller en funktion som "lins" snarare än som "spegel". Teorin hjälper oss att se och tänka om världen, snarare än att fungera som en representation av den (s. 44). Den är viktig för att just kunna blottlägga, ifrågasätta och rubba, och Alvesson och Deetz (1999) länkar samman den kritiska traditionen med bland annat Frankfurtskolan, postmodernismen, feministisk teori och vissa modernare former av marxism (s. 42). Den kritiska forskningen riktar inte bara den kritiska blicken utåt, utan också inåt, mot vetenskapen i sig. Forskaren förstås inte som betraktare eller beskrivare av hur världen är beskaffad, utan som delaktig i hur den beskaffas. Denna självkritiska vetenskapsteoretiska blick är en viktig grund för tanken om forskningens möjlighet att påverka och förändra, eftersom den genererar vetenskapligt ansvarstagande för antaganden som befäster och upprätthåller maktpositioner.

Alvesson och Deetz (1999) pekar alltså mot en forskningstradition som inte bara syftar till att undersöka, utan som också avser att förändra. Dessa ambitioner återfinns med tydlighet inom genusvetenskapen, men också inom exempelvis postkolonial, queer- och cripforskning. Den är dock enligt min erfarenhet mindre artikulerad i socialt arbete. Detta trots att socialt arbete är länkat till ett verksamhetsfält och till politisk aktivitet och trots att forskningsfältet exempelvis beskrivits i relation till uppdraget att bedriva studier av "sociala problem och åtgärder för att lösa dessa" samt bidra med 
kunskaper som kan omsättas i "förebyggande åtgärder" och "praktiska verksamheter" (se Brante 1987 s. 39). En koppling som enligt mig borde skapa utrymme för en kritisk samhällsvetenskaplig grund. Det jag vill undersöka, med genusvetenskapen som jämförande exempel, är därför hur vi kan förstå att den kritiska samhällsvetenskapliga traditionen inte har en starkare tradition i socialt arbete. Låt mig börja med att ge en bild av socialt arbete och genusvetenskap som forskningsområden.

\section{Praktikerfält och kunskapsbehov}

Idén om en specifik kunskapsgrund för det sociala arbetet, det vill säga om ett socialt arbete med en egen forskningsbaserad kunskapsbas i stället för inhämtade kunskaper från näraliggande ämnen (som t.ex sociologi och psykologi), grundades i Sverige under 1960-talet. Sedan tidigare fanns Institutet för socialpolitisk och kommunal utbildning i Stockholm, Göteborg och Lund, men nu grundlades socialhögskolorna och socionomtiteln. Socionomexamen blev likvärdig med andra akademiska examina och socialt arbete förtydligades som ämne och professionellt område. Utifrån det utvecklades idén om ett specifikt forskningsbaserat kunskapsområde för socionomer. Under 1970-och 1980-talen tillsattes professurer i ämnet och forskarutbildningar sjösattes. Genom forskning och utbildning skulle socialarbetarnas professionella kompetens fördjupas och stärkas (Bäck-Wiklund 1993; Nygren 2016; Sunesson 2016).

I en bemärkelse kan forskningen i socialt arbete sägas ha utvecklats som ett svar på rop från fältet. Målet var att stärka socialarbetarprofessionen och att genom vetenskapligt baserad kunskap generera en möjlig socialarbetaridentitet som kunde hävda sig gentemot andra professioner. Socialarbetare och fackliga organisationer argumenterade med denna utgångspunkt för betydelsen av forskning. Parallellt fanns även ett generellt kunskapsbehov i samhället. Sociala problem behövde förklaras, förebyggas och lösas, vilket det inte minst fanns ett politiskt intresse för. Socialt arbete skulle byggas upp tvärvetenskapligt och fånga upp kunskaper från ämnen som var centrala för socionomutbildningen, exempelvis psykologi, sociologi, socialrätt, social metodik (Grinups 1999 s. 90; Nygren 2016 s. 134ff.).

Forskningsfältets tvärvetenskaplighet och koppling till praktikerfältet kan vara en förklaring till hur det förhållit sig till teori. Sociologen Thomas Brante (2003) har tydliggjort hur ämnet socialt arbete saknar egen teoretisk grund och därför behöver låna teorier från andra näraliggande ämnen, som exempelvis sociologi och psykologi (se t.ex. s. 158ff.), även om många diskussioner om teorier i och för socialt arbete har förts (se t.ex. Börjeson 1984; Swedner 1983). Spännvidden i ämnets teoretiska behov är dock stor, sociala problem behöver förklaras och förstås inom en rad olika områden och på flera olika nivåer. Det är inte enkelt att lyfta fram vilka teoretiker som varit och/eller är centrala för forskningen i socialt arbete, teorianvändningen är 
alltför mångfacetterad (se t.ex. Brante 2003 s. 140ff., 158ff.; Dellgran \& Höjer 2013 s. 107ff.). Även om det finns teoretiker som ofta används inom forskningen, skulle det sannolikt vara mycket svårt att generera en överenskommelse kring vilka teoretiker som utgör dess teoretiska kanon (jfr Brante 2003 s. 158ff.). Detta till trots menar jag att det finns ett antal namn som tenderar att lyftas fram som tongivande i förhållande till det sociala arbetets idétradition. Utmärkande för dem är att de egentligen inte refererar till en vetenskaplig tradition, utan snarare knyter an till praktikerfältet. Jane Addams och Mary Richmond, båda verksamma mot slutet av 1800-talet och centrala för att teoretisera kring praktiskt socialt arbete, lyfts ofta fram som förgrundsgestalter i tänkandet om socialt arbete (se t.ex Meeuwisse \& Swärd 2016 s. 34ff.; Soydan 1994). Teoretiskt har även Malcolm Paynes (2015) arbete om modern teoribildning för (praktiskt) socialt arbete kommit att fungera som något av ett standardverk. Gemensamt för samtliga är att fokus riktas mot hur socialt arbete kan "utföras" mer än hur det kan analyseras. Samtligas starka koppling till praktiskt socialt arbete menar jag kan tjäna som en indikation på hur centralt verksamhetsfältet är för hur socialt arbete formuleras teoretiskt. Teori i socialt arbete handlar både om teori för det praktiska görandet och för vetenskapligt analytiskt arbete.

\section{Kvinnorörelsen som påtryckare}

I Sverige har genusvetenskapen sina rötter i den forskning som initierades av kvinnorörelsen under 1970-talet. Rörelsen påtalade att forskning om kvinnors livssammanhang behövdes, eftersom de tidigare osynliggjorts i både samhälle och vetenskap. Runt om vid landets universitet startade seminarieverksamheter och kurser om kvinnofrågor (Thurén 2003 s. 28). Målet var att utveckla teoretisk, praktisk, politisk och vetenskaplig kunskap om kvinnors levnadsvillkor. Det som initialt kallades kvinnoforskning, och som i dag kallas genusforskning, fokuserade på att synliggöra kvinnors villkor i jämförelse med det manliga kollektivets politiska, ekonomiska och sociala status. Forskningen visade att kvinnors situation var sämre än mäns, samtidigt som kvinnors och mäns livssammanhang var ömsesidigt beroende av varandra. Forskning kom successivt allt mer att ta fasta på just relationen mellan kvinnor och män och de samhälleliga maktstrukturer som påverkade denna, snarare än att ensidigt belysa kvinnors situation. Samhällets könsmönster blottlades genom empiriska studier och genererade en teoretisk diskurs som fokuserade på att förklara samhällets könsordning (Gothlin 1999 s. 14; Grinups 1999 s. 92-93; Thurén 2003 s. 21ff.).

Genusforskningen är i dag mångfacetterad och rymmer forskning med tydligt fokus på könsmaktsrelationer, men också forskning om kvinnor och män med betydligt mindre eller avsaknad av sådant fokus. Fältet inkluderar också exempelvis sexualitetsforskning, maskulinitetsforskning och queerstudier (Gothlin 1999 s. 13-14; 
Thurén 2003 s. 19ff.). Fältet kan betraktas som väl etablerat vetenskapligt. Det har både professorer, forskarutbildningar samt kurser på grund- och avancerad nivå (Högskoleverket 2007).

Den internationella feministiska och genusteoretiska teoribildningen är central för fältet. Det finns en grundläggande feministisk teoretisk kanon som utvecklats och utvecklas genom en rad feministiska forskares arbeten. Exempelvis genom Sylvia Walbys, Shulamit Firestones, Cathrine MacKinnons och Gayatri Chakravorty Spivaks diskussioner som ger olika perspektiv på och förståelser av könsmaktsfrågor. Det finns också en rad centrala vetenskapskritiska arbeten som formulerar feministiska vetenskapspositioner, exempelvis av Dorothy Smith, Sandra Harding, Patricia Hill Collins och Donna Haraway. Bara för att nämna några. Det teoretiska feministiska fältet utvecklas kontinuerligt. Under de senaste åren har teoriutveckling drivits av exempelvis Judith Butler, Karen Barad och Sara Ahmed. Påtagligt är att inom det genusvetenskapliga fältet finns teoretiska verk och pågående teoretiska diskussioner som är både samhälls- och vetenskapskritiska. Det är svårt att se att det finns motsvarande teoretiska kanon inom forskningsfältet socialt arbete, något jag indikerat ovan och återkommer till. Först ska jag dock stanna upp och lyfta fram den likhet som finns i hur de båda fälten relaterar till demokratiska grunder och strukturell förändring.

\section{Demokratiska grunder och strukturell förändring}

Både forskningsområdet socialt arbete och genusvetenskapen är alltså sprungna ur politiska och ideologiska rörelser, något som också gör att båda är sammanlänkade med politiska ambitioner och grundläggande demokratiska antaganden. Grinups (1999) påpekar att ett uttryck för det sociala arbetets politiska och demokratiska förankring är socialtjänstlagen. Den ger ett tydligt uttryck för en politisk och demokratisk inramning för många av det sociala arbetets praktiska verksamheter där människors sociala och ekonomiska trygghet ska främjas såväl som jämlikhet i levnadsvillkor (s. 94; se även Brante 2003 s. 163ff.). Även de etiska riktlinjer som formulerats för socionomer återspeglar liknande värderingar om människors lika värde (t.ex. SSR 2017). Dessa grunder påtalas som särskilt viktiga för socialt arbete i dag, eftersom samhället präglas av ökade ojämlikheter och individualiserad förståelse av sociala problem (se t.ex. Dahlstedt \& Lalander 2018 s. 20). Även om forskningen i socialt arbete givetvis inte styrs av varken socialtjänstlagen eller de professionsetiska koderna, innebär kopplingen till det praktiska verksamhetsfältet att forskningen förväntas bidra med kunskap till detta praktiska förändringsarbete (jfr Nygren 2016 s. 134ff.). På liknande sätt kan den genusvetenskapliga forskningen länkas till politiska och demokratiska ambitioner som formuleras bland annat i diskrimineringslagen och jämställdhetspolitiken (jfr Grinups 1999 s. 94). För båda forskningsområdena finns alltså en koppling 
till ideologiska, politiska och demokratiska grunder som tar avstamp i mål om jämlikhet och jämställdhet. En viktig skillnad är att i förhållande till socialt arbete finns en konkret handlingsarena genom yrkesverksamma socionomer och verksamhetsfältet, där kunskap kan omsättas och praktiseras. Den genusvetenskapliga forskningen har inte haft ett motsvarande fält, även om vi på senare år sett en framväxt av exempelvis genus- och jämställdhetskonsulter. De kan återfinnas som privata aktörer men också som kommunalt anställda verksamhetsutvecklare med inriktning mot exempelvis jämställdhet och likabehandling inom socialtjänsten. De båda forskningsfälten kan alltså i dag ibland mötas på praktikerfältet. Värt att uppmärksamma är att när forskningen i socialt arbete etablerades uppfattades närheten till praktikerfältet som något av en utmaning. En av dem som diskuterade detta var Margareta Bäck-Wiklund (1993), forskare i socialt arbete, som påtalade att anknytningen till fältet riskerade att skapa identitetsproblem för forskarna samt leda till påtryckningar från fältet - något som kunde göra forskningen och forskarna mindre kritiska (t.ex. s. 12, 29). Grinups (1999) såg på liknande sätt problem och påpekade att närheten kan generera teorilöshet och en okritiskhet mot de system som beforskas (s. 91).

Ytterligare en likhet mellan områdena, grundad i de ideologiska utgångpunkterna, är intresset för strukturella samhällsaspekter. Den genusvetenskapliga forskningen har fokus mot strukturell ojämlikhet mellan könen och avser att bidra med kunskap som förmår förändra dessa förhållanden. Socialt arbete utgår på delvis liknande sätt mer eller mindre explicit från idéer om ett klassamhälle med ojämlik fördelning av resurser, social utslagning, marginalisering och utsatthet. En central del av forskningen inom fältet berör på olika sätt hur samhället som system skapar utsatthet och ojämlikhet. Jag menar att ett sätt att förstå både det praktiska sociala arbetet och forskningen i socialt arbete är att de utgår från en idé om att bidra till att utjämna ojämlikheter i människors levnadsvillkor (Brante 1987 s. 39; Nygren 2016). Det innebär i en mening ett intresse för strukturella nivåer och strukturell samhällsförändring.

Inom båda forskningsområdena finns alltså ett fokus mot att vetenskapligt bidra till att utveckla förklarings- och förståelsemodeller om samhällets medverkan till enskilda människors livssituation. Utgångspunkten i socialt arbete har ofta varit att fånga sociala problem på flera olika nivåer, men som Grinups (1999) påpekar redan under sent 1990-tal finns en risk att samhällsnivån försvinner i analyserna (s. 95ff.). Under senare år kan detta sägas ha konkretiserats genom den allt starkare betoningen på att utveckla evidensbaserade metoder som ofta har individinriktat fokus. Inom genusvetenskapen är den strukturella nivån mer explicit uttalad genom ämnets fokus på ojämlikheten mellan könen. Det förankras också genom teoribildning som på ett eller annat sätt utgår från förståelser av kön som en maktstruktur (Thurén $2003 \mathrm{~s}$. 20). Historikern och genusvetaren Sara Edenheim (2018) har dock kritiserat den svenska genusvetenskapliga forskningen för att bli allt mer identitetspolitisk snarare 
än att utgå från centrala frågor om makt och strukturell ojämlikhet, något hon menar gör att ämnet riskerar att tappa sitt centrala fokus. Det är alltså möjligt att både socialt arbete och genusvetenskapen i dag tappat fokus mot synliggörande och problematisering av strukturell ojämlikhet och förtryck, och att därmed båda tar (ännu) ett steg bort från den kritiska samhällsvetenskapliga traditionen.

\section{Med eller utan vetenskapskritik}

En påtaglig skillnad mellan forskningen i socialt arbete och genusvetenskapen är deras olika förhållningssätt till vetenskapen. Medan den genusvetenskapliga forskningen har en lång tradition av att vara vetenskapskritisk, menar jag att motsvarande tradition inom socialt arbete inte är lika tydlig. Genusvetenskapen har genom centrala feministiska teoretiker skrivit in sig i och bidragit till den kritiska vetenskapliga traditionen. Exempelvis har feministiska teoretiker problematiserat vetenskapens möjligheter att generera forskning som är opartisk, neutral och objektiv (se t.ex. Haraway 1988; Harding 1986; Smith 1999). Därmed har de också utvecklat en vetenskapsteoretisk position som möjliggör en förening mellan det vetenskapliga och det samhällsförändrande projekt de vill driva. Motsvarande vetenskapliga diskussioner är svåra att finna inom socialt arbete där få metodologiska eller vetenskapsteoretiska diskussioner egentligen förts. Metodböcker som varit och är viktiga har förvisso publicerats både av och för forskare i socialt arbete (t.ex. Eliasson 1987; Jönson 2010; Meeuwisse, Swärd, Eliasson-Lappalainen \& Jacobsson 2008), men få av dem ansluter sig tydligt till en kritisk tradition. Ett undantag är Rosmari Eliassons, ${ }^{1}$ forskare i socialt arbete. Hon gör i sin bok Forskningsetik och perspektivval en ansats till en kritisk position genom att definiera att forskningens funktion "kan eller bör vara att bidra till förändring och utveckling" (Eliasson 1987 s. 99), men utvecklar dock inte resonemanget mycket mer än så. Brante (1987) visar också att det under ämnets initiala formering fanns en vetenskapskritisk ådra hos de första professorerna i socialt arbete. Flera av dem problematiserade exempelvis vetenskapens värdeimpregnering och idealet om forskarens objektivitet och neutralitet (s. 51). Dessa kritiska tankegångar hade definitivt kunnat bli en grogrund för mer vidareutvecklade kritiska diskussioner. Några mer utvecklande resonemang om detta är dock svåra att finna inom socialt arbete. Det är också värt att uppmärksamma att även om det tycks ha funnits en bred förståelse av vetenskap och ett kritiskt förhållningssätt gentemot vetenskapliga ideal om objektivitet och neutralitet, så tycks denna förståelse också ha haft sina gränser. Viss vetenskap tycks trots allt ha förståtts som mer problematiskt värdeimpregnerad än annan. Så sent som i början av 2000-talet är det uppenbart att gränsen mellan

1 Sedermera Eliasson-Lappalainen. 
vetenskap och politik är viktig att dra för flertalet av de dåvarande professorer i socialt arbete som sociologen Thomas Brante (2003) intervjuade i syftet att undersöka ämnets innehåll och utveckling. Flera av de som intervjuades uppfattade feminism som en problematisk vetenskaplig position (s. 163ff.). Med tanke på fokus i den här artikeln är det naturligtvis en viktig pusselbit för att förstå den kritiska forskningens position inom socialt arbete. Frågan är hur långt en vetenskapskritisk diskussion hade kunnat nå i socialt arbete, om betydelsen av att tydliggöra gränsen mellan det vetenskapliga och icke-vetenskapliga trots allt var så angelägen att dra, och när den gränsen så tydligt drogs och uteslöt en av de mest etablerade kritiska samhällsvetenskapliga forskningspositionerna.

\section{Att våga vara en kritisk vetenskap}

Likheterna mellan forskningsfältet socialt arbete och genusvetenskapen är alltså flera. Båda relaterar till praktiska fält samt härrör från politiska och ideologiska rörelser: det sociala arbetet och kvinnorörelsen. De inkluderar samhällsförändrande ambitioner, det vill säga har i mer eller mindre bemärkelse emancipatoriska syften, något jag menar skulle kunna bana väg för en tydligare etablering av den kritiska forskningstraditionen som Alvesson och Deetz (1999) förespråkar också i socialt arbete. Samtidigt finns konkreta olikheter i hur områdena positionerat sig och utvecklats, något som skapar skilda förutsättningar för deras möjlighet att som vetenskaper knyta an till den kritiska traditionen. En påtaglig skillnad är hur vetenskapsteoretiska diskussioner förts inom fälten. Medan genusvetenskapen utvecklat en vetenskapsteoretisk och metodologisk diskussion som möjliggör en kritisk positionering, saknas egentligen sådana diskussioner i socialt arbete. Avsaknaden av en problematisering av traditionella vetenskapliga ideal om objektivitet och krav på frikoppling från värderingar, gör att forskningen igen och igen tvingas hantera en balansgång mellan att å ena sidan vara sammanlänkad med ambitioner om förändring och utveckling och å andra sidan kunna passera som objektiv och värderingsfri - en kombination som den traditionella akademin inte ser som möjlig, utan ovetenskaplig (jfr Brante 1987 s. 31). Genom att genusvetenskapen utvecklat en vetenskapskritisk tradition som tydliggör hur all forskning, inte bara den som har förändringsambitioner, är påverkad av sina teoretiska utgångspunkter och forskarens positioner, kan de problematisera sådana antaganden om vad vetenskap är och kan vara. Den möjliggör därmed en position där vetenskap och förändringsambitioner kan förenas, vilket gör det möjligt att bedriva kritisk samhällsvetenskaplig forskning.

Det kan vara så att genusvetenskapen haft hjälp av att i grunden vara en uttalat normativ vetenskap, som vill förändra samhällets könsojämlikhet. Socialt arbete har inte riktigt haft motsvarande artikulerade ambitioner att utvecklas kring. 
Genusvetenskapen har genom sin normativitet förenats kring ett nav som kretsar runt könsordningen i samhället och förståelsen av att kön konstrueras socialt och kulturellt på individ-, organisations- och samhällsnivå. Den förenas också genom antaganden om att vetenskapen inte står fri från maktordningar eller könsgöranden (jfr Thuren 2003 s. 19-20). Detta kan antas ha bidragit till egen teoriutveckling och vetenskapskritiska diskussioner. Socialt arbete skulle på liknande sätt kunna definieras som en normativ vetenskap, med en vilja att påverka (klass)ojämlika samhällsförhållanden. Det sammanhållande inom socialt arbete har dock snarare varit det empiriskt breda område som beforskas (som är svårt att definiera [jfr Sunesson 2016] men som slarvigt kan beskrivas som sociala problem och socialt arbete). Drivkraften för att teoriutveckling och vetenskapskritik har kanske därmed också varit svagare?

Det kan också vara närheten mellan forskningsområdet och verksamhetsfältet socialt arbete som genererar en försiktighet bland forskare vad gäller att positionera sig tydligt inom den kritiska traditionen. Att just närheten till fältet kanske genererar behov av gränssättning mot det som riskerar att uppfattas som ovetenskapligt. Närheten till fältet har funnits som en rädsla inom ämnet och har påtalats som en risk för att forskare förlorar distans, objektivitet och forskaridentitet (jfr Brante 1987 s. 30ff., 2003 s. 163ff.; Bäck-Wiklund 1993 s. 29; Grinups 1999 s. 91). Medan genusvetenskapen och den kritiska forskningen satt sig på tvären och problematiserat sådana misstänkliggöranden om ovetenskaplighet, är mitt intryck att socialt arbete i stället försökt leva upp till traditionella vetenskapliga ideal. Detta genom att bland annat ta avstånd från samhällsförändrande (politiska) ambitioner. Kanske är det också det som generat ett visst avståndstagande mot feministisk positionering inom socialt arbete? Om feminism inte uppfattas som vetenskapligt möjlig, vilket tycks ha varit fallet inom socialt arbete (jfr Brante 2003 s. 164ff.), blir den svår att släppa in i fältet eftersom den skapar en risk för att tappa vetenskaplig legitimitet. Kanske gäller samma tveksamhet andra kritiska perspektiv, som exempelvis de redan nämnda postkolonialistiska queer- och criptraditionerna.

Jag menar dock att socialt arbete som forskningsområde skulle tjäna på att utveckla en tydligare kritisk samhällsvetenskaplig tradition och genom att föra kritiska vetenskapsteoretiska diskussioner. Det skulle möjliggöra en starkare vetenskaplig positionering och en kritisk blick på de problem vi beforskar. En ökad användning av de kritiska ramverk som genusvetenskap, postkolonialism och queer- och criptraditionerna erbjuder, skulle göra det möjligt att analysera sociala problem i förhållande till strukturell ojämlikhet relaterad till kön, sexualitet, klass, etnicitet, funktion och ålder. Det skulle generera angelägen kunskap med kapacitet att bidra till ett mer jämlikt och rättvist samhälle. 


\section{Referenser}

Alvesson, Mats \& Deetz, Stanley (1999) Kritisk samhällsvetenskapligmetod. Lund: Studentlitteratur. Brante, Thomas (1987) Konstitueringen av nya vetenskapliga fält. Exemplet forskning i socialt arbete. Sociologisk forskning, 24(4): 30-60.

Brante, Thomas (2003) Konsolideringen av nya vetenskapliga fält. Exemplet socialt arbete. I: Högskoleverket. Socialt arbete. En nationell genomlysning av ämnet. Högskoleverkets rapportserie 2003:16R: 135-197.

Bäck-Wiklund, Margareta (1993) Vetenskap och politik i socialt arbete. Rapport 1993:8. Göteborgs universitet, Institutionen för socialt arbete.

Börjeson, Bengt (1984) Om socialt arbete som kunskapsområde. Umeå universitet, Institutionen för socialt arbete.

Dahlstedt, Magnus \& Lalander, Philip (2018) Inledning. I: Magnus Dahlstedt \& Philip Lalander (red.) Manifest för socialt arbete. För ett socialt arbete i tiden. Lund: Studentlitteratur.

Dellgran, Peter \& Höjer, Staffan (2006) "Pluralism på gott och ont? Om forskningen och den akademiska kunskapsproduktionen i socialt arbete. I: Meeuwisse, Anna, Sunesson, Sune \& Swärd, Hans (red.) Socialt arbete: En grundbok. Stockholm: Natur \& Kultur.

Dellgran, Peter \& Höjer, Staffan (2013) Kunskapsbildning som praktik och politik. Om socialt arbete som forskningsämne. I: Björn Blom, Stefan Morén \& Lennart Nygren (red.) Kunskap i socialt arbete. Om villkor, processer och användning. Stockholm: Natur \& Kultur.

Edenheim, Sara (2018) Den goda viljans feminism. En kritisk analys av ett paradigm. Genusvetenskaplig tidskrift, januari.

Ekström, Veronica (2016) Det besvärliga våldet. Socialtjänstens stöd till kvinnor som utsatts för våld $i$ nära relationer. Linköping: Linköping studies in art and science, no 689.

Eliassi, Barzoo (2010) A stranger in my homeland. The politics of belonging among youth people with Kurdish backgrounds in Sweden. Sundsvall: Mittuniversitetet, Institutionen för socialt arbete.

Eliasson, Rosmari (1987) Forskningsetik och perspektivval. Lund: Studentlitteratur.

Gothlin, Eva (1999) Kön eller genus? Göteborg: Nationella sekretariatet för genusforskning.

Grinups, Berit Sundgren (1999) Har ämnet socialt arbete och feministisk forskning något gemensamt? I: Margareta Bäck-Wiklund \& Lennart Nygren (red.) Vetandets villkor. Socialt arbete som kunskapsområde, 89-100. Umeå universitet/Göteborgs universitet.

Haraway, Donna (1988) Situated knowledge. The science question in feminism and the privilege of partial perspective. Feminist studies, 14(3): 575-599.

Harding, Sandra (1986) The science question in feminism. Milton Keynes: Open University Press.

Herz, Marcus (2012) Från ideal till ideologi. Konstruktioner av kön och etnicitet inom socialtjänsten. Örebro universitet: Örebro Studies in Social Work 13.

Högskoleverket (2007) Utvärdering av ämnet genusvetenskap vid svenska universitet och högskolor. Rapport 2007:17R.

Johansson, Helena (2006) Brist på manliga förebilder. Dekonstruktion av en föreställning och en praktik. Skriftserie 2006:4. Göteborgs universitet, Institutionen för socialt arbete.

Jönson, Håkan (2010) Sociala problem som perspektiv. En ansats för forskning och socialt arbete. Malmö: Liber.

Meeuwisse, Anna \& Swärd, Hans (2016) Vad är socialt arbete? I: Anna Meeuwisse, Hans Swärd, Sune Sunesson \& Marcus Knutagård (red.) Socialt arbete. En grundbok, 29-76. Stockholm: Natur \& Kultur.

Meeuwisse, Anna, Swärd, Hans, Eliasson-Lappalainen, Rosmari \& Jacobsson, Katarina (2008) 
Forskningsmetodik för socialvetare. Stockholm: Natur \& Kultur.

Nygren, Lennart (2016) Socialt arbete i praktik, forskning och utbildning. I: Anna Meeuwisse, Hans Swärd, Sune Sunesson \& Marcus Knutagård (red.) Socialt arbete. En grundbok, 128-145. Stockholm: Natur \& Kultur.

Payne, Malcolm (2015) Modern teoribildning i socialt arbete. Stockholm: Natur \& Kultur.

Smith, Dorothy (1999) Woman's perspective as a radical critique of sociology. I: Helen E. Longino \& Evelyn Fox Keller (red.) Feminism and science, 17-27. Oxford: Oxford University Press.

Smirthwaite, Goldina (2005) Genusvetenskap. Vad är det för ämne egentligen? I: Gunnel Forsberg \& Cristina Grenholm (red.) ... och likväl rör det sig. Genusrelationer i förändring. Karlstad: Karlstad University Press.

Soydan, Haluk (1994) Det sociala arbetets idéhistoria. Lund: Studentlitteratur.

SSR (2017) Etik i socialt arbete. Etisk kod för socialarbetare. Akademikerförbundet SSR. Internetkälla 2019-12-17:https://akademssr.se/sites/default/files/files/etik_och_socialt_arbete_2017_w.pdf

Sunesson, Sune (2016) Socialt arbete som internationellt forskningsområde. I: Anna Meeuwisse, Hans Swärd, Sune Sunesson \& Marcus Knutagård (red.) Socialt arbete. En grundbok, 146-159. Stockholm: Natur \& Kultur.

Swedner, Harald (1983) Socialt arbete. En tankeram. Lund: Liber.

Söderman, Emma (2019) Resistance through acting. Ambivalent practices of the no border musical. Lund university, Lund dissertation in social work.

Thurén, Britt-Marie (2003) Genusforskning: Frågor, villkor och utmaningar. Vetenskapsrådet. Stockholm.

Wikström, Hanna (2007) (O)möjliga positioner. Familjer från Iran \& postkoloniala reflektioner. Skriftserien 2007:2. Göteborgs universitet, Institutionen för socialt arbete. 